\section{The oral health status of adults with a visual impairment, their dental care and oral health information needs}

\author{
E. K. Watson, ${ }^{1}$ D. R. Moles, ${ }^{2}$ N. Kumar ${ }^{3}$ and S. R. Porter ${ }^{4}$
}

IN BRIEF

- The proportion of the population who have a visual impairment is increasing.

- This study highlights specific dental health issues and information needs of this vulnerable group.

- While the study group had better oral hygiene practices than the Adult Dental Health Survey group, their oral health was no better.

- There were issues with the provision of dental information in an accessible format.

\begin{abstract}
Aim There is little information available concerning the impact of visual impairment upon oral health. The present study sought to identify the oral health and experiences of adults with a visual impairment together with the nature, source and access to oral health information. In addition the study evaluated the oral health status of a group of individuals with a visual impairment with respect to oral health markers, treatment choice and attendance patterns in comparison to a reference group from the general population in the United Kingdom. Method One hundred adults with a visual impairment were examined and completed a questionnaire concerning their experience of oral health care and available information sources. The information collected was directly compared with data from the Adult Dental Health Survey 1998 for the south region of England. Results The present group of individuals with a visual impairment had better oral hygiene practices, and similar levels of oral hygiene and hard tissue disease to those of a comparable group of the Adult Dental Health Survey 1998 (ADHS 1998). However 24\% of those with a visual impairment were not registered with a dentist and $26 \%$ of the patients wished for appropriate information concerning oral health care. Conclusions There is a need to develop oral health promotion that ensures patients with a visual impairment have appropriate information regarding oral health care and its provision.
\end{abstract}

\section{INTRODUCTION}

Approximately two million people living in the United Kingdom (UK) have a significant visual impairment ranging from low vision to blindness, $90 \%$ of these individuals are over 60 years of age. ${ }^{1}$ The aetiology of visual impairment varies with different population groups. In the developing world the most common cause of visual impairment is untreated cataract. ${ }^{2}$ In developed countries the most common cause of visual impairment is cited as agerelated macular degeneration. ${ }^{3}$ Ethnicity also has an impact on visual impairment altering the incidence of visual impairment as well as the predominant cause.,4

"Specialist in Special Care Dentistry, Postgraduate, UCL Eastman Dental Institute; ${ }^{2}$ Professor of Oral Health Services Research \& Director of Postgraduate Education and Research, Peninsula Dental School; ${ }^{3}$ Consultant and Honorary Lecturer, UCL Eastman Dental Institute; ${ }^{4}$ Institute Director and Professor of Oral Medicine, UCL Eastman Dental Institute

*Correspondence to: E. Watson

Email:katewatsonuk@yahoo.co.uk

Online article number E15

Refereed Paper - accepted 19 February 2010

DOI: $10.1038 /$ sj.bdj.2010.395

${ }^{\circledR}$ British Dental Journal 2010; 208: E15
Despite the relatively high prevalence of visual impairment there is little information available regarding the dental health care and needs of such individuals. Some reports suggest that oral health is reduced in individuals with a visual impairment, 5,6 whilst others contradict this. ${ }^{7,8}$

Visual impairment may impact on oral health through physical, social or informational barriers related to the impairment, attendant medical conditions or lack of information in a suitable format. Other barriers include lack of services, lack of transport, inadequate resources or financial considerations, lack of social awareness, or lack of education and training of service providers. ${ }^{9,10}$ There are very few studies that have examined the health information needs of visually impaired individuals and even fewer have investigated the dental health information needs of this group. ${ }^{11}$ In relation to dental prescribing, the European Commission has recognised the need for pharmaceutical information to be more accessible to people with a visual impairment. ${ }^{12}$ This applies equally to a dentist who may be prescribing medications to visually impaired adults.
In order to determine the oral health care needs of individuals with a visual impairment there is a need to establish the oral health status and experiences of such groups with respect to dentistry. Hence the aims of this study were to determine the oral health status and previous dental heath care experiences of a group of individuals with a visual impairment. The oral health status of the group with a visual impairment was compared with a relevant subgroup of data from the Adult Dental Health Survey (ADHS) 1998. ${ }^{13}$

\section{MATERIALS AND METHOD}

\section{Study group}

The study group participants were recruited from the Low Vision Aid (LVA) clinic at Moorfields Eye Hospital, London, UK, between November 2004 and January 2005 and consisted of 100 randomly selected adults with a visual impairment. Prospective participants were approached by one dentally qualified clinician. All patients attending the LVA clinic were approached. Information concerning the study was provided in large print, Braille, 
audio-cassette and in different languages upon request. The participants gave informed consent to take part in the study and the Ethics Committee of Moorfields Hospital granted ethical approval. All participants were given a unique identifier. Each participant completed an interview based upon a questionnaire designed in consultation with the Royal National Institute of Blind People (RNIB) that addressed a series of key issues concerning previous dental health care experience and oral hygiene regimes of the participants. All questions for comparison with the reference group were identically worded to those of the ADHS 1998 to ensure comparability with the reference group.

Each participant had a visual, noninvasive oral examination to determine their oral health status. All examinations were performed using clinic lighting and an additional intra-oral light source. Disposable examination gloves and mirrors were used. Examinations were non-invasive and consisted of a visual inspection only. Each tooth was charted accordingly, with a positive or negative score for the presence or absence of plaque and calculus. Data was recorded for each participant on an identical data recording sheet. Each participant was immediately informed of their oral health status. Those persons with likely oral disease were advised to seek further examination with their dentist. Those without a dentist were given information regarding appropriate services and their general medical practitioner informed.

All interviews and oral examinations were carried out by the same dentally qualified clinician.

\section{Statistical analyses}

The study data from the sample group were analysed using Microsoft Excel, SPSS statistics package (www.spss.com) and STATA statistics package (www.stata.com). All data were compared to the South England area from the ADHS raw data set, which was obtained from the UK Data Archive (www.dataarchive.co.uk). The age distribution of the sample studied varied from the reference group in the ADHS 1998. In view of this and in line with standard epidemiological practice there was a need to age standardise the study group in relation

\begin{tabular}{|c|c|c|c|c|c|c|c|c|}
\hline & $16-24$ & $25-34$ & $35-44$ & $45-54$ & $55-64$ & $65-74$ & $75+$ & Total \\
\hline $\begin{array}{l}\text { ADHS } 1998 \\
\text { interviewed }\end{array}$ & 177 & 339 & 302 & 273 & 214 & 179 & 121 & 1,605 \\
\hline Percentage & $11 \%$ & $21 \%$ & $19 \%$ & $17 \%$ & $13 \%$ & $11 \%$ & $8 \%$ & $100 \%$ \\
\hline $\begin{array}{l}\text { ADHS } 1998 \text { exam } \\
\text { and interviewed }\end{array}$ & 122 & 246 & 207 & 201 & 145 & 109 & 44 & 1,074 \\
\hline Percentage & $11 \%$ & $23 \%$ & $19 \%$ & $19 \%$ & $14 \%$ & $10 \%$ & $4 \%$ & $100 \%$ \\
\hline $\begin{array}{l}\text { Visually impaired } \\
\text { sample }\end{array}$ & 2 & 4 & 5 & 7 & 9 & 19 & 54 & 100 \\
\hline Percentage & $2 \%$ & $4 \%$ & $5 \%$ & $7 \%$ & $9 \%$ & $19 \%$ & $54 \%$ & $100 \%$ \\
\hline
\end{tabular}

to the ADHS 1998 South of England reference group. Individual age standardisations were carried out for each of the variables selected using STATA statistics package. Indirect age standardisation was used as the age specific rates were based on small numbers of participants (Table 1).

\section{RESULTS}

\section{Demographics and characteristics}

One hundred and twenty-one adults with a visual impairment were approached initially. Eight individuals declined to participate and 13 were unable to participate. There was thus a response rate of $82 \%$. The final study group comprised of 55 females and 45 males with over half the group being greater than 75 years of age. Seventy percent of the study sample described themselves as White British, 5\% as Other White, 4\% Indian, 2\% Pakistani/ Bangladeshi, 6\% from Black backgrounds and 13\% from other ethnic groups.

The age at which the study sample became visually impaired varied from birth to 92 years with a median of 52 years. Fifteen percent had a visual impairment from birth, the remainder having acquired impairment. Five of the fifteen with congenital disease had albinism, while prematurity accounted for the loss of vision in two. Of the 85 who had a visual loss due to an acquired disease, 33 had a visual impairment as a consequence of age-related macular degeneration, 7 from trauma, 4 from thrombotic episodes, 4 from cataract, 4 from glaucoma, 21 from a combination of the aforementioned causes, 3 from diabetes mellitus and 9 from other causes. Fourteen patients were registered with the local authority or RNIB as partially-sighted and 23 were registered as blind. In this study group it was estimated that up to $70 \%$ of the participants may be eligible for registration based on examination of their visual acuity scores. The RNIB had similarly reported that approximately two thirds of those who are eligible to register as blind or partially sighted are not, ${ }^{1}$ which may have an impact on access to services and additional community and social support.

The patients had a wide range of attendant medical problems, the most common of which were musculoskeletal diseases, notably arthritis (affecting 55 patients). Fifty-six of the patients had a spectrum of cardiovascular disorders including known hypertension (36 patients), current angina pectoris (15 patients) and previous myocardial infarction (5 patients). Other commonly reported diseases affected the gastrointestinal tract (28 patients), endocrine (27 patients, of which 19 had diabetes mellitus), neurological (11 patients) and renal systems (8 patients). Two patients had hearing loss as well as a visual impairment. Eighty-five percent of the patients were taking regular medications for the above mentioned, and often attendant, disease.

\section{Sources of oral healthcare}

Seventy-six percent of the study sample reported being presently registered with a dental practitioner. The most common past or presently utilised dental services were NHS general dental practitioners (88\%), hospital or salaried dental services (6\%) and private dental services (6\%).

The group cited a variety of difficulties in accessing dental care; these included a 
lack of NHS general dental practitioners, difficulty locating NHS dental services, and the expense of dental care. Many who had been receiving regular dental care had been attending the same dentist for many years. Twenty-four percent of participants were not registered with a dentist and 3\% did not know how to go about obtaining dental care.

Participants in the study used a variety of visual aids to assist daily life. Of the individuals questioned, 90\% used a magnifier, 86\% could read large print with and some without the use of a magnifier, 50\% of the sample used audio-cassettes and $27 \%$ had the facilities to use electronic material. Braille was only used by 3\% of participants and none used Moon (an alternative to Braille). Fifty-one percent of the group believed that there was inadequate information concerning dental care available in a format appropriate for their visual impairment. Twenty-six percent of the group would have liked more information on dental care in another format, these tending to be the younger individuals.

\section{Age standardised comparison with the Adult Dental Health Survey 1998}

The age-standardised measures of dental status among those with a visual impairment (VI ASR) compared with relevant elements of the 1998 Adult Dental Health Survey are detailed in Tables 1-4. Results are statistically significant at $\mathrm{p}<0.05$ if the 95\% CI for the ASR does not include the Adult Dental Health Survey rate.

\section{Education}

When standardised for age, the group with visual impairment had significantly lower educational achievements than the ADHS reference group with respect to the attainment of a degree or higher (ADHS 57\% to VI ASR 34\%); however they were less likely to have no qualifications at all (ADHS 26\% to VI ASR 16\%) (Table 2).

\section{Dental care service use}

The group with a visual impairment was significantly less likely to have accessed private dental care than the reference group (ADHS 25\% to VI ASR 6\%), however there was no significant difference in their access of NHS or other dental care services (Table 2).

\section{Table 2 Age standardised results table ñ proportions for questionnaire}

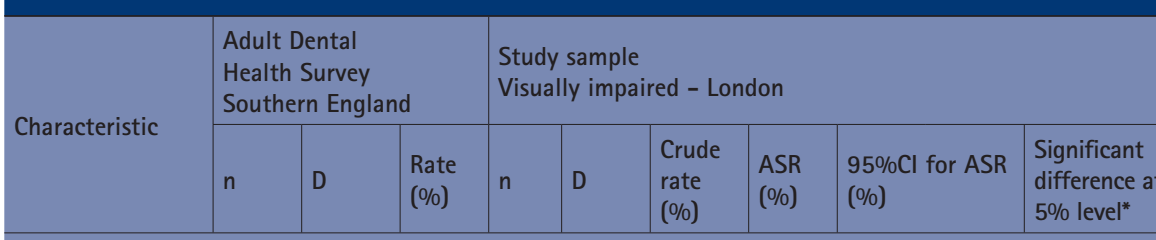

Dental attendance

\begin{tabular}{l|l|l|l|l|l|l|l|l|l|l}
\hline Regular check up & 861 & 1,605 & 53.6 & 38 & 100 & 38.0 & 37.0 & 26.0 & 51.0 & Yes \\
\hline $\begin{array}{l}\text { Occasional } \\
\text { check up }\end{array}$ & 148 & 1,605 & 9.2 & 8 & 100 & 8.0 & 15.0 & 6.0 & 29.0 & No \\
\hline $\begin{array}{l}\text { Only with } \\
\text { trouble }\end{array}$ & 389 & 1,605 & 24.2 & 52 & 100 & 52.0 & 59.0 & 44.0 & 78.0 & Yes \\
\hline Never & 1094 & 1,605 & 68.2 & 87 & 100 & 87.0 & 85.0 & 68.0 & 100.0 & No \\
\hline NHS & 396 & 1,605 & 24.7 & 6 & 100 & 6.0 & 6.0 & 2.0 & 14.0 & Yes \\
\hline Private & 101 & 1,605 & 6.3 & 6 & 100 & 6.0 & 7.0 & 2.0 & 15.0 & No \\
\hline Other & & & & ${ }^{\dagger} 1$ & & & & & &
\end{tabular}

\section{Treatment preferences}

\begin{tabular}{l|l|l|l|l|l|l|l|l|l|l}
\hline $\begin{array}{l}\text { Aching back } \\
\text { tooth extracted }\end{array}$ & 239 & 1,605 & 14.9 & 37 & 100 & 37.0 & 37.0 & 26.0 & 51.0 & Yes \\
\hline $\begin{array}{l}\text { Aching back } \\
\text { tooth restored }\end{array}$ & 1202 & 1,605 & 74.9 & 60 & 100 & 60.0 & 94.0 & 72.0 & 100.0 & No \\
\hline Don't know & 92 & 1,605 & 5.7 & 35 & 100 & 35.0 & 20.0 & 14.0 & 28.0 & Yes \\
\hline $\begin{array}{l}\text { Aching front } \\
\text { tooth extracted }\end{array}$ & 92.0 & 1,605 & 84.0 & 62 & 100 & 62.0 & 99.0 & 76.0 & 100.0 & No \\
\hline $\begin{array}{l}\text { Aching front } \\
\text { tooth restored }\end{array}$ & 1348 & & & $\ddagger 3$ & & & & & & \\
\hline \begin{tabular}{l} 
Don't know \\
\hline
\end{tabular}
\end{tabular}

\section{Treatment need}

\begin{tabular}{l|l|l|l|l|l|l|l|l|l|l}
\hline Need treatment & 573 & 1,605 & 35.7 & 33 & 100 & 33.0 & 52.0 & 36.0 & 74.0 & No \\
\hline $\begin{array}{l}\text { Don't need } \\
\text { treatment }\end{array}$ & 740 & 1,605 & 46.1 & 63 & 100 & 63.0 & 82.0 & 63.0 & 100.0 & Yes \\
\hline Don't know & 49 & 1,605 & 3.1 & 4 & 100 & 4.0 & 5.0 & 1.0 & 13.0 & No \\
\hline
\end{tabular}

Oral hygiene procedures

\begin{tabular}{l|l|l|l|l|l|l|l|l|l|l}
\hline TB 2+ times & 1116 & 1,605 & 69.5 & 67 & 100 & 67.0 & 96.0 & 74.0 & 100.0 & Yes \\
\hline TB 1 time & 287 & 1,605 & 17.9 & 31 & 100 & 31.0 & 38.0 & 26.0 & 54.0 & Yes \\
\hline TB >1 time & 51 & 1,605 & 3.2 & 2 & 100 & 2.0 & 5.0 & 0 & 18.0 & No \\
\hline TB never & 1 & 1,605 & 0.1 & 0 & 100 & 0 & 0 & 0 & 0 & No \\
\hline TB/paste only & 619 & 1,605 & 38.6 & 40 & 100 & 40.0 & 48.0 & 34.0 & 65.0 & No \\
\hline Floss & 401 & 1,605 & 25.0 & 24 & 100 & 2.0 & 49.0 & 31.0 & 73.0 & Yes \\
\hline Mouthwash & 219 & 1,605 & 13.6 & 31 & 100 & 31.0 & 74.0 & 50.0 & 100.0 & Yes \\
\hline All OH aids & 827 & 1,605 & 51.5 & 53 & 100 & 53.0 & 88.0 & 66.0 & 100.0 & Yes \\
\hline
\end{tabular}

Educational attainment

\begin{tabular}{l|c|c|c|c|c|c|c|c|c|c}
\hline $\begin{array}{l}\text { No educational } \\
\text { qualification }\end{array}$ & 421 & 1,605 & 26.2 & 33 & 100 & 33.0 & 16.0 & 11.0 & 22.0 & Yes \\
\hline $\begin{array}{l}\text { Degree level } \\
\text { or above }\end{array}$ & 917 & 1,605 & 57.1 & 21 & 100 & 21.0 & 34.0 & 21.0 & 52.0 & Yes \\
\hline
\end{tabular}

$n=$ number of people with characteristic; $D=$ denominator (total eligible people); ASR = Age Standardised Rate (study group data standardised to Adult Dental Health Survey, Southern England age profile); $\mathrm{TB}=$ Toothbrushing

*Results are statistically significant at $p<0.05$ if the $95 \% \mathrm{Cl}$ for the ASR does not include the Adult Dental Health Survey rate

¥Those marked don't know/never/no preference were excluded from the calculations 


\section{Regular dental attendance}

When standardised for age, the group with a visual impairment was significantly ( $p<0.05$ ) less likely to attend for regular dental checkups than the ADHS reference group (ADHS 54\% versus VI ASR 37\%). The group with a visual impairment were more likely to attend a dentist as a consequence of an acute dental problem (59\%) than the ADHS reference group (24\%) (Table 2).

\section{Choice of dental treatment}

The group with a visual impairment were more likely than the reference group to request extraction of an aching posterior tooth (ADHS 15\% versus VI ASR 37\%) or anterior tooth (ADHS 6\% versus VI ASR 20\%) rather than seek restoration (Table 2).

\section{Oral hygiene practices}

The group with a visual impairment were more likely to brush their teeth two or more times a day compared with the ADHS reference group (ADHS 70\% versus VI ASR $96 \%$ ). The group with a visual impairment was also significantly more likely to use oral hygiene aids (ADHS 52\% to VI ASR 88\%) including dental floss (ADHS 25\% to VI ASR 49\%) and mouthwashes (ADHS 14\% to VI ASR 74\%) (Table 2).

\section{Oral hygiene status}

The frequencies of visible plaque and calculus were generally lower in the group with a visual impairment as compared to the ADHS group. However, this difference was not statistically significant (Table 3).

\section{Dentures and edentulousness}

The frequency of edentulousness in the group with a visual impairment was lower than that of the ADHS cohort (ADHS 9\% to VI ASR 6\%). However there were no significant differences in the frequency of wearing full or partial dentures between the two groups (Table 3).

\section{Decayed, missing and filled teeth (DMFT)}

There was no significant difference between the two groups with respect to individuals having 21 or more teeth (ADHS 86\% versus VI ASR 91\%) and both groups had a comparable mean numbers of teeth (ADHS 25, VI ASR 25). However moderate tooth

\begin{tabular}{|c|c|c|c|c|c|c|c|c|c|c|}
\hline \multirow{2}{*}{ Characteristic } & \multicolumn{3}{|c|}{$\begin{array}{l}\text { Adult Dental } \\
\text { Health Survey } \\
\text { Southern England }\end{array}$} & \multicolumn{7}{|c|}{$\begin{array}{l}\text { Study sample } \\
\text { Visually impaired - London }\end{array}$} \\
\hline & $n$ & D & $\begin{array}{l}\text { Rate } \\
(\%)\end{array}$ & $n$ & D & $\begin{array}{l}\text { Crude } \\
\text { rate } \\
(\%)\end{array}$ & $\begin{array}{l}\text { ASR } \\
(\%)\end{array}$ & \multicolumn{2}{|c|}{$\begin{array}{l}\text { 95\%Cl for ASR } \\
(\%)\end{array}$} & $\begin{array}{l}\text { Significant } \\
\text { difference at } \\
5 \% \text { level }^{*}\end{array}$ \\
\hline \multicolumn{11}{|l|}{ Dentate status } \\
\hline $\begin{array}{l}\text { Those with } \\
21+\text { teeth }\end{array}$ & 920 & 1,074 & 85.7 & 45 & 78 & 58.0 & 91.0 & 66.0 & 100.0 & No \\
\hline Edentulous & 149 & 1,605 & 9.3 & 22 & 100 & 22.0 & 5.7 & 3.6 & 8.6 & Yes \\
\hline Natural teeth only & 928 & 1,074 & 86.4 & 48 & 78 & 61.5 & 84.2 & 62.0 & 100.0 & No \\
\hline $\begin{array}{l}\text { Natural teeth } \\
\text { and dentures }\end{array}$ & 145 & 1,074 & 13.5 & 28 & 78 & 36.0 & 13.0 & 9.0 & 19.0 & No \\
\hline \multicolumn{11}{|l|}{ Denture wearing } \\
\hline Complete upper & 27 & 1,074 & 2.5 & 9 & 78 & 11.0 & 4.0 & 2.0 & 8.0 & No \\
\hline Complete lower & 7 & 1,074 & 0.7 & 1 & 78 & 1.0 & 0 & 0 & 2.0 & No \\
\hline Partial upper & 126 & 1,074 & 11.7 & 18 & 78 & 23.0 & 9.0 & 5.0 & 14.0 & No \\
\hline Partial lower & 53 & 1,074 & 4.9 & 18 & 78 & 23.0 & 7.0 & 4.0 & 11.0 & No \\
\hline \multicolumn{11}{|l|}{ Tooth wear } \\
\hline Wear moderate & 128 & 1,074 & 11.9 & 8 & 78 & 10.0 & 4.0 & 2.0 & 9.0 & Yes \\
\hline Wear severe & 13 & 1,074 & 1.2 & 1 & 78 & 1.0 & 0 & 0 & 2.0 & No \\
\hline \multicolumn{11}{|l|}{ Oral hygiene } \\
\hline Visible plaque & 795 & 1,074 & 74.0 & 46 & 78 & 59.0 & 60.0 & 44.0 & 80.0 & No \\
\hline Visible calculus & 706 & 1,074 & 65.7 & 44 & 78 & 56.0 & 55.0 & 40.0 & 73.0 & No \\
\hline \multicolumn{11}{|c|}{$\begin{array}{l}n=\text { number of people with characteristic } \\
D=\text { denominator (total eligible people) } \\
\text { ASR }=\text { Age Standardised Rate (Study group data standardised to Adult Dental Health Survey, Southern England age profile) } \\
\text { * Results are statistically significant at } p<0.05 \text { if the } 95 \% \mathrm{Cl} \text { for the ASR does not include the Adult Dental Health Survey rate }\end{array}$} \\
\hline
\end{tabular}

\begin{tabular}{|c|c|c|c|c|c|c|c|}
\hline \multirow{2}{*}{ Characteristic } & \multicolumn{2}{|c|}{$\begin{array}{l}\text { Adult Dental } \\
\text { Health Survey } \\
\text { Southern England }\end{array}$} & \multicolumn{5}{|c|}{$\begin{array}{l}\text { Study sample } \\
\text { Visually impaired - London }\end{array}$} \\
\hline & D & Mean & D & $\begin{array}{l}\text { Crude } \\
\text { mean }\end{array}$ & $\begin{array}{l}\text { Age } \\
\text { standardised } \\
\text { mean }\end{array}$ & $\begin{array}{l}95 \% \mathrm{Cl} \text { for } \\
\text { Age stand- } \\
\text { ardised mean }\end{array}$ & $\begin{array}{l}\text { Significant } \\
\text { difference } \\
\text { at } 5 \% \text { level }^{*}\end{array}$ \\
\hline \multicolumn{8}{|l|}{ DMFT } \\
\hline Number of teeth & 1,074 & 25.2 & 78 & 20.2 & 24.9 & $14.6,32.0$ & No \\
\hline $\begin{array}{l}\text { Number of sound/ } \\
\text { untreated teeth }\end{array}$ & 1,074 & 15.4 & 78 & 11.8 & 18.4 & $9.8,30.1$ & No \\
\hline $\begin{array}{l}\text { Number of decayed/ } \\
\text { untreated teeth }\end{array}$ & 1,074 & 1.3 & 78 & 0.9 & 0.5 & $0.0,7.1$ & No \\
\hline $\begin{array}{l}\text { Number of restored/ } \\
\text { sound teeth }\end{array}$ & 1,074 & 9.3 & 78 & 7.5 & 6.1 & $2.1,15.0$ & No \\
\hline
\end{tabular}

wear was significantly $(\mathrm{p}<0.05)$ higher in the ADHS reference group than the group with a visual impairment (ADHS 12\% versus VI ASR 4\%). The mean number of sound and untreated teeth was comparable between the two groups (ADHS 15 versus
VI ASR 18). There were no significant differences in the mean number of decayed and untreated teeth (ADHS 1.3 versus VI ASR 0.5) nor the mean number of restored and sound teeth (ADHS 9 versus VI ASR 6) (Table 4). 


\section{DISCUSSION}

This is the first detailed investigation of the aspects of oral healthcare and oral health status of individuals with a visual impairment residing in the United Kingdom. The group of adults with a visual impairment are generally representative of the age ${ }^{1}$ and gender ${ }^{14}$ of those likely to have such impairment, although there was a higher representation of congenital visual disease (15\%) as compared to national UK data. ${ }^{1}$ This higher frequency of congenital visual impairment probably reflects the referral patterns of the patients to the Low Vision Aid clinic of Moorfields Eye Hospital, London. However, the present group of patients did provide a general representation of common acquired causes of visual loss.

Although the medical status of individuals was not detailed in the ADHS 1998 the present group of patients had a high frequency and wide range of systemic disorders that could variably impact upon oral health care provision, notably rheumatoid disease (causing difficulties in accessing the dental surgery), cardiovascular disease (that may complicate treatment provision and limit the use of general anaesthesia) and endocrine disease (particularly diabetes mellitus that may necessitate altered appointment scheduling and additional monitoring procedures). ${ }^{15}$ Furthermore, although not detailed in the present report, some of the medication of the attendants systemic disease could give rise to adverse oral effects (for example, gingival enlargement with calcium channel blockers, lichenoid disease with sulphonylureas and beta blockers, and angioedema with angiotensin converting enzyme (ACE) inhibitors). ${ }^{16}$

The individuals with a visual impairment were as likely as those within the ADHS to attend an NHS dentist. However, some who did not have a dentist did not know how to find one. This is of course not unique to individuals with a visual impairment but $51 \%$ of this group believed that there was inadequate information concerning dental healthcare, and 26\% were without information in a format appropriate to their visual loss. There would seem to be a need to ensure that information is available widely in formats that do not disadvantage individuals with a visual impairment. There is clearly a need to provide information in several formats as only $23 \%$ of this group were able to read normal sized text, and only $3 \%$ of the study group could read Braille.

In view of the fact that many of the present group of individuals with a visual impairment were beyond retirement age, it is difficult to provide a clear history of employment. However the trends of individual employment in the study group reflect those reported in groups with a visual impairment in the United States $^{4}$ and the United Kingdom. ${ }^{17,18}$ This lower employment rate could potentially adversely affect the ability to pay for dental healthcare, and similarly reflect the lower rates of registration of partially sighted $(14 \%)$ or blind (23\%) people. As observed in this group, and as suggested by other sources, ${ }^{19}$ there is a potential for these unregistered individuals to not receive the additional community and health support to which they may be entitled.

Despite the aforementioned potential barriers to oral healthcare provision, the group of individuals with a visual impairment did not have any significantly greater oral health needs than a comparable group of UK adults. This may of course reflect a bias due to the type of individual who attends the LVA clinic, who may have a more active interest in their health. The present results accord with those of a previous study of younger adults. ${ }^{7}$ The present group of individuals with a visual impairment were more likely to regularly clean their teeth and use adjunctive aids such as dental floss and mouthwashes than the comparable group, thus suggesting that there is a desire by the individuals with a visual impairment to maintain good oral health. Studies with children that have a visual impairment also suggest that loss of vision is not a hindrance to wanting good oral health or improved dental aesthetics and function..$^{20}$

Oral health is unlikely to significantly affect visual loss; however it may potentially reduce the severity of attendant disease. Of significance to many patients with acquired visual impairment, the treatment of periodontitis may reduce the risk of atherosclerosis and hence hypertension and ischaemic heart disease. ${ }^{21}$ Oral health may also influence the metabolic changes of diabetes mellitus. ${ }^{22}$ Hence good oral hygiene may not only decrease the risk of dental disease, but also systemic disease in people with a visual impairment.

The results of the present investigation reveal that despite potential barriers to the receipt of information concerning the provision of oral health care, the dental status of individuals with congenital or acquired visual impairment is similar to that of the general population There are conflicting data however; while individuals with a visual impairment may be more likely to regularly clean their teeth than the general population, they are also more likely to have a tooth extracted than restored. The reasons for these conflicting results are unknown, but could reflect perceived difficulties in obtaining information on, or treatment for, dental disease. Although the present results reveal that visual impairment does not significantly adversely affect oral health, the group in this study did have unmet dental needs and certainly had some experience of dental disease. Hence the future goal would surely be to develop healthcare strategies that ensure all people with a visual loss have access to relevant information on oral health maintenance, in all appropriate formats, and have ready access to oral health care providers.

\section{RECOMMENDATIONS}

There is little research concerning the oral health status of individuals with a visual impairment and thus more studies are required in order to make definitive conclusions. However, from this study, there appears to be a need for information concerning oral healthcare to be available more widely in different formats for people with a visual impairment.

The authors would like to thank all the staff and patients at Moorfields Eye Hospital, London who assisted and participated in this study.

1. The Royal national Institute for the Blind (2001) Improving Lives: Priorities in Health and Social Care for Blind and Partially Sighted People. London, Royal National Institute for the Blind.

2. World Health Organization. World health report 1998. Chapter 2: measuring health. Geneva: World Health Organization, 1998. http://www.who.int/ whr/1998/whr98_ch2.pdf (accessed 10 November 2008).

3. Apte R S, Scheufele T A, Blomquist P H. Etiology of blindness in an urban community hospital setting. Ophthalmology 2001; 108: 693-696.

4. American Foundation for the Blind (2004) Blindness statistics. http://www.afb.org/Section.as p?Section $\mid D=15 \&$ Topic $\mid D=413 \&$ Document $\mid D=4385$ (accessed $10^{\text {th }}$ November 2008).

5. Anaise J Z. Periodontal disease and oral hygiene in a group of blind and sighted Israeli teenagers 14-17 years of age. Community Dent Oral Epidemiol $1979 ; 7: 353-356$. 
6. Dios P D. Oral care in the blind and visually impaired. In Porter S R, Scully C (eds) Oral health care for those with HIV Infection and other special needs. pp 219-221. Northwood: Science Reviews, 1995.

7. Greeley C B, Goldstein P A, Forrester D J. Oral manifestations in a group of blind students. ASCD J Dent Child 1976; 26: 39-41.

8. Shyama M, Al-Mutawa S A, Morris R E, Sugathan, T, Honkala E. Dental caries experience of disabled children and young adults in Kuwait. Community Dent Health 2001; 18: 181-186.

9. Lebowitz E J. An introduction to dentistry for the blind. Dent Clin North Am 1974; 18: 651-659.

10. Edwards D M, Merry A J. Disability part 2: access to dental services for disabled people. A questionnaire survey of dental practices in Merseyside. Br Dent J 2002; 193: 253-255.

11. Beverley C A, Bath P A, Booth A. Health information needs of visually impaired people: a systematic review of the literature. Health Soc Care Community 2004; 12: 1-24.
12. European Commission (2004). http://ec.europa.eu/ enterprise/sectors/pharmaceuticals/files/pharmacos/ docs/doc2005/04_05/braille text20050411_en.pdf

13. Office for National Statistics. Adult dental health survey. Oral health in the United Kingdom 1998. London: The Stationery Office, 1998.

14. World Health Organisation. Visual impairment and blindness. Fact Sheet No. 282. Geneva: World Health Organization, 2005. http://www.who. int/mediacentre/factsheets/fs282/en/index.html (accessed 10 November 2008).

15. Scully C, Diaz P D, Kumar N. Special care in dentistry. Handbook of oral health care. pp137-143. 272-277; 385-390. London: Churchill Livingston, 2006.

16. Scully C, Bagan J V. Adverse drug reactions in the orofacial region. Crit Rev Oral Biol Med 2004; 15: 221-239.

17. Chou S L, Misajon R, Gallo J, Keeffe J E. Measurement of indirect costs for people with vision impairment. Clin Experiment Ophthalmol 2003; 31: 336-340.
18. Department of Health. Registered blind and partially sighted people. Year ending 31 March 2003. England. London: Department of Health, 2003. http://www.dh.gov.uk/PublicationsAndStatistics/ Statistics/StatisticalWorkAreas/StatisticalSocialCare/ StatisticalSocialCareArticle/fs/en?CONTENT_

ID=4082697\&tchk=NrtmK1 (accessed 10 November 2008).

19. Royal National Institute for the Blind. See change. London: Royal National Institute for the Blind, 2003.

20. AlShareed M, Bedi R, Hunt N P. The views and attitudes of parents of children with a sensory impairment towards orthodontic care. Eur J Orthod 2004; 26: 87-91.

21. Genco R, Offenbacher S, Beck J. Periodontal disease and cardiovascular disease. Epidemiology and possible mechanisms. J Am Dent Assoc 2002; 133(Suppl 1): 14S-22S.

22. Mealey B L, Oates T W. Diabetes mellitus and periodontal diseases. J Periodonto/ 2006; 77: 1289-1303. 